\title{
SPINA BIFIDA - A RETROSPECTIVE STUDY
}

\section{Amandeep Kaur ${ }^{1}$, Mahesh Sharma ${ }^{2}$}

${ }^{1}$ Demonstrator, Department of Anatomy, Government Medical College \& Hospital, Anatomy Department, E- block, Sector 32-, Chandigarh, India.

${ }^{* 2}$ Professor \& Head of the Department, MBBS, MS Human Anatomy, Government Medical College \& Hospital, Anatomy Department, E- block, Sector 32-, Chandigarh, India.

\section{ABSTRACT}

Background: The occurrence of congenital anomalies is increasing in the present era. The incidence is estimated to be $3-7 \%$ of the congenital disorders.

Aim: The present study is focused on the spina bifida and to know the incidence of spinal defects in north Indian population. This study will be helpful for providing baseline data from the north Indian population.

Methodology: The present study was done on 1400 fetuses which were sent by gynecology and obstetrics department of GMCH Sec. 32, Chandigarh to anatomy department for autopsy purpose during period of 2008 to 2017. In every case, location and morphology of spinal defects were observed.

Results: The present study showed $11.7 \%$ cases with spinal defects, out of these, $1.2 \%$ spina bifida closed (occulta) and $10.5 \%$ spina bifida open defects were noted which included $1.2 \%$ ventral spinal defects, $31.7 \%$ with meningocele, $24.3 \%$ myelomeningocele, $28.6 \%$ myelocele and $12.8 \%$ with rachischisis.

Conclusions: It is important to note the detection of congenital anomalies in early stage of gestation. It is advantageous for the obstetrician in planning the line of management whether to continue the pregnancy or not. KEY WORDS: Congenital Anomalies, Spinal defects, Meningocele, Myelomeningocele, Myelocele, Rachischisis.

Address for Correspondence: Dr. Mahesh Kumar Sharma, Professor \& Head of the Department, MBBS, MS Human Anatomy, Government Medical College \& Hospital, Anatomy Department, Eblock, Sector 32-, Chandigarh (India); 160030, contact no: 9646121529, Phone no: +91-0172-266523, Faxno: +91-0172-2609360 E-Mail: drmahesh1965@gmail.com

Access this Article online

Quick Response code

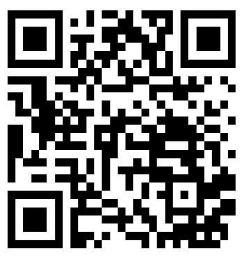

DOI: $10.16965 /$ ijar.2019.124
Journal Information

International Journal of Anatomy and Research

ICV for 2016 ISSN (E) 2321-4287 | ISSN (P) 2321-8967

90.30

https://www.ijmhr.org/ijar.htm

DOI-Prefix: https://dx.doi.org/10.16965/ijar

\section{Article Information}

Received: 28 Jan 2019

Peer Review: 28 Jan 2019

Revised: None
Accepted: 07 Mar 2019

Published (O): 05 Apr 2019

Published (P): 05 Apr 2019

\section{INTRODUCTION}

Increasing cases of congenital anomalies are of a big concern today. The estimated $3-7 \%$ incidence of congenital disorders is considered to be false due to the fact that there occurs under reporting's from the developing countries [1]. These congenital malformations (CMF) are a common cause of perinatal deaths accounting for $10-15 \%$ in underdeveloped nations [2]. Neural tube defects (NTDs) are one of the CMF's leading to still births, neonatal and infant deaths and in some cases lifelong disabilities. These defects are secondary to abnormal closure of the neural tube during embryonic development and are classified according to their location where they are present. They may be spinal NTDs (spina bifida) and cranial NTDs (cranioschisis) [3-5]. Spinal defects are the most complex malformations in human. Spina bifida is of types: Spina bifida closed and spina bifida open. In spina bifida occulta (closed) is a defect 
associated with failure of fusion of posterior arches of vertebrae, where neural tissue never comes out. This defect is covered by both skin and hair and it is mainly noted in lumbo-sacral region, (10\% of normal people) [6].

Spina bifida cystica (open) is a severe type of deformity in which nervous tissue get protruded out of the unfused vertebral arches and is covered by meningeal sac. Spina bifida cystica is of two types: 1. Meningocele: in this type of defect only meninges goes out without any nervous tissue. 2. Myelomeningocele: in this type of defect in which meninges along with nervous tissue is present out of the vertebral defect. Spina bifida aperta (myelocele) is a type in which nervous tissue is directly exposed externally without any meningeal sac. Rachischisis is a defect in which neural never elevate but remain as a flattened mass. This type of defect is associated with whole length of vertebral column [6].

Ventral spinal defects are the ones in which vertebrae are open in front resulting in abnormalities of NTDs of the spinal cord may involve the meninges, vertebrae, muscles and skin. The most common and severe form of spina bifida is myelomeningocele (MMC), here spinal cord is open dorsally which form placode on the back of the fetus. Person having MMC often shows motor as well as sensory neurological deficit distal to the lesion. This may lead to lower extremity weakness and if it persists for longer time it may causes paralysis. Pressure sores are the major cause of sensory involvement. Spinal defects are also associated with orthopedic abnormalities including talipes (club foot), contractures, hip dislocation, scoliosis and kyphosis are also observed commonly [7].

Considering this situation, our study was focused on preparing a baseline data for congenital spinal anomalies in the north Indian population which might be beneficial for such defects in coming future. Study will be helpful for obstetrician to decide whether to continue or terminate the pregnancy where NTDs are found.

\section{MATERIALS AND METHODS}

The retrospective study was done in the department of Anatomy, Government Medical College
\& Hospital (GMCH) sector 32, Chandigarh, on 1400 fetuses from the period of 2008 to 2017. These fetuses were sent from the gynecology and obstetrics department for autopsy purpose after obtaining approval from college ethics committee. The fetuses were embalmed and fixed with formalin and later studied for spinal defects in detail. In this study, spinal defects were defined as malformations assumed to be a consequence of defective closure of neural tube in embryonic period. In every case, location and morphology of spinal defects were observed according to guidelines of Langmann's embryology book [8]. The other parameters gestational age, sex and associated anomalies were noted. Fetuses were photographed and their findings were appropriately documented as described in table no:1 [9-11].

\section{RESULTS}

Out of 1400 fetuses, 164 [11.7\%] cases were found with spinal defect. Out of 164 cases, 75 [45.7\%] fetuses were females and 89 [54.2\%] fetuses were male. The gestational age of the spinal defects ranged from 14 to 29 weeks. Spinal defects classified according to a classification based on principles previously described in Table no: 1 along with number of defect cases were found in the present study [9-11]

Fig. 1: Showing spina bifida occulta on thoracolumber region.

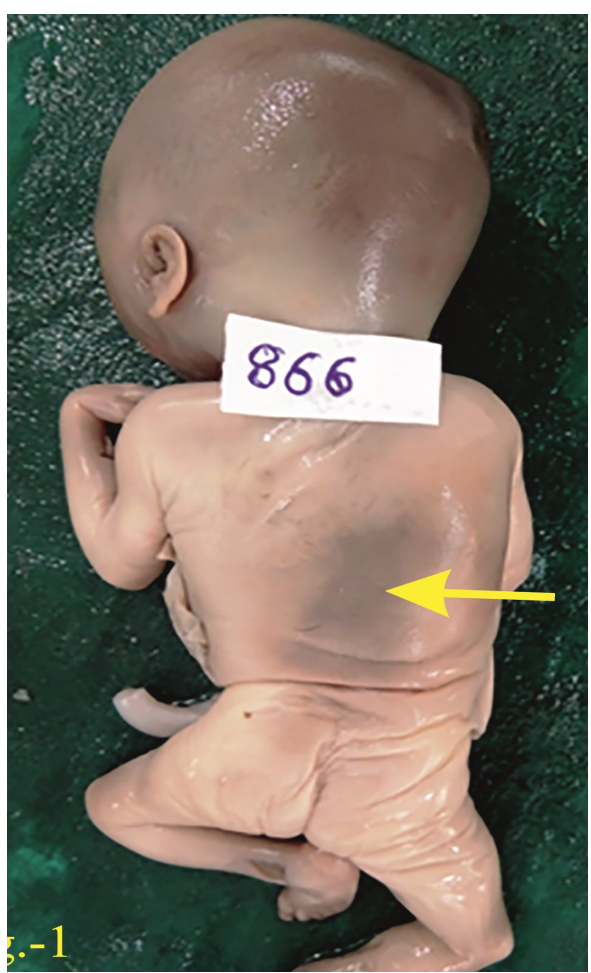


Distribution of spinal tube defects (STDs): According to the exact location, distribution of STDs is given in [table no: 2], the most common location of spina bifida was recorded on thoracolumbar region. Out of 164 cases $(11.7 \%)$, it was observed that 52 cases [31.7\%] with meningocele (figure no: 2.1 ), 40 cases [24.3\%] with myelomeningocele (figure no: 2.2), 47 cases [28.6\%] with myelocele (figure no: 3 ), and 21 cases [12.8\%] with rachischisis (figure no: 5 ). Two cases with [1.2\%] with spina bifida occulta (figure no: 1 ) and two cases [1.2\%] with ventral spinal defect (figure no: 4) were seen .

Associated morphological anomalies: Out of 164 cases with spinal defects, 116 [70\%] cases were found with associated morphological anomalies (table 3).

Fig. 2.1 \& 2.2: Showing meningocele and myelomeningocele spinal defects.

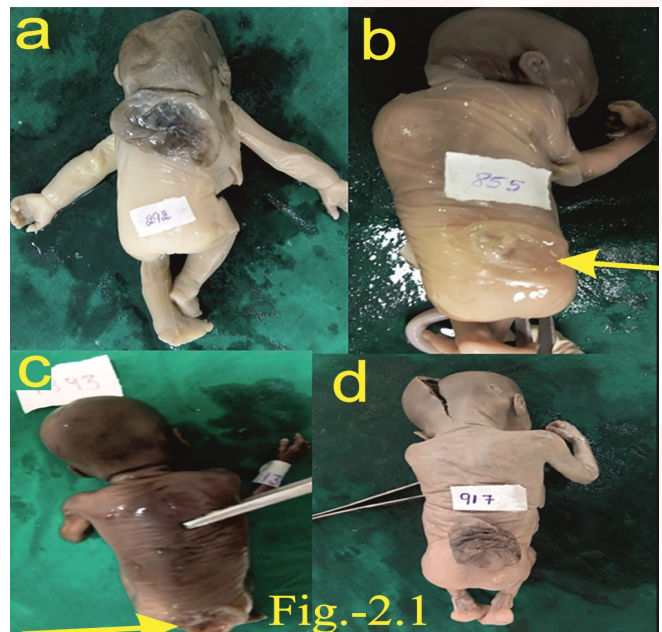

Fig. 2.1: Showing meningocele on (a) cervicothoacic region (b) lumber region (c) sacral region

(d) lumbosacral region.

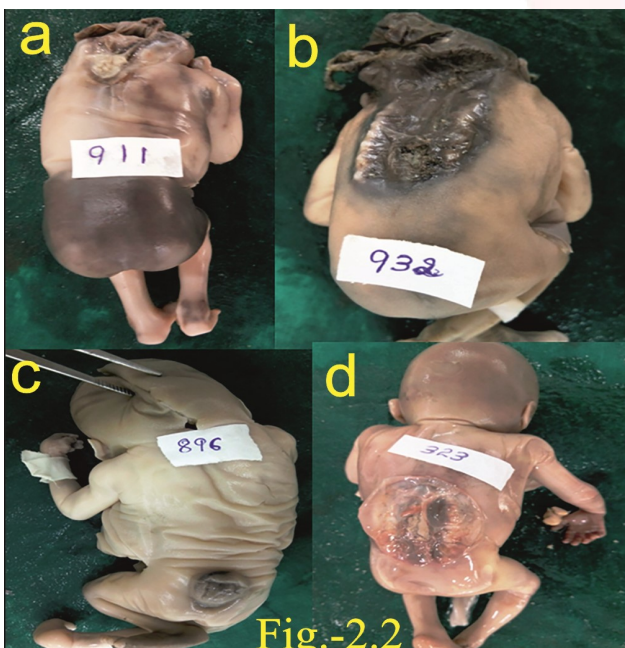

Fig. 2.2: Showing myelomeningocele on (a) cervical region (b) cervicothoracic region (c) sacral region (d) lumber region. Associated malformation also showing in a \& b (Fig.-2.2) myelomeningocele with anencephaly.
Fig. 3: showing myelocele on (a, b) cervical region (c) thoracic region (d) lumber region (e) sacral region ( $f$ ) cervicothoracic region. Associated malformation also showing in a, b, c \& f (Fig.-3) myelocele with anencephaly.
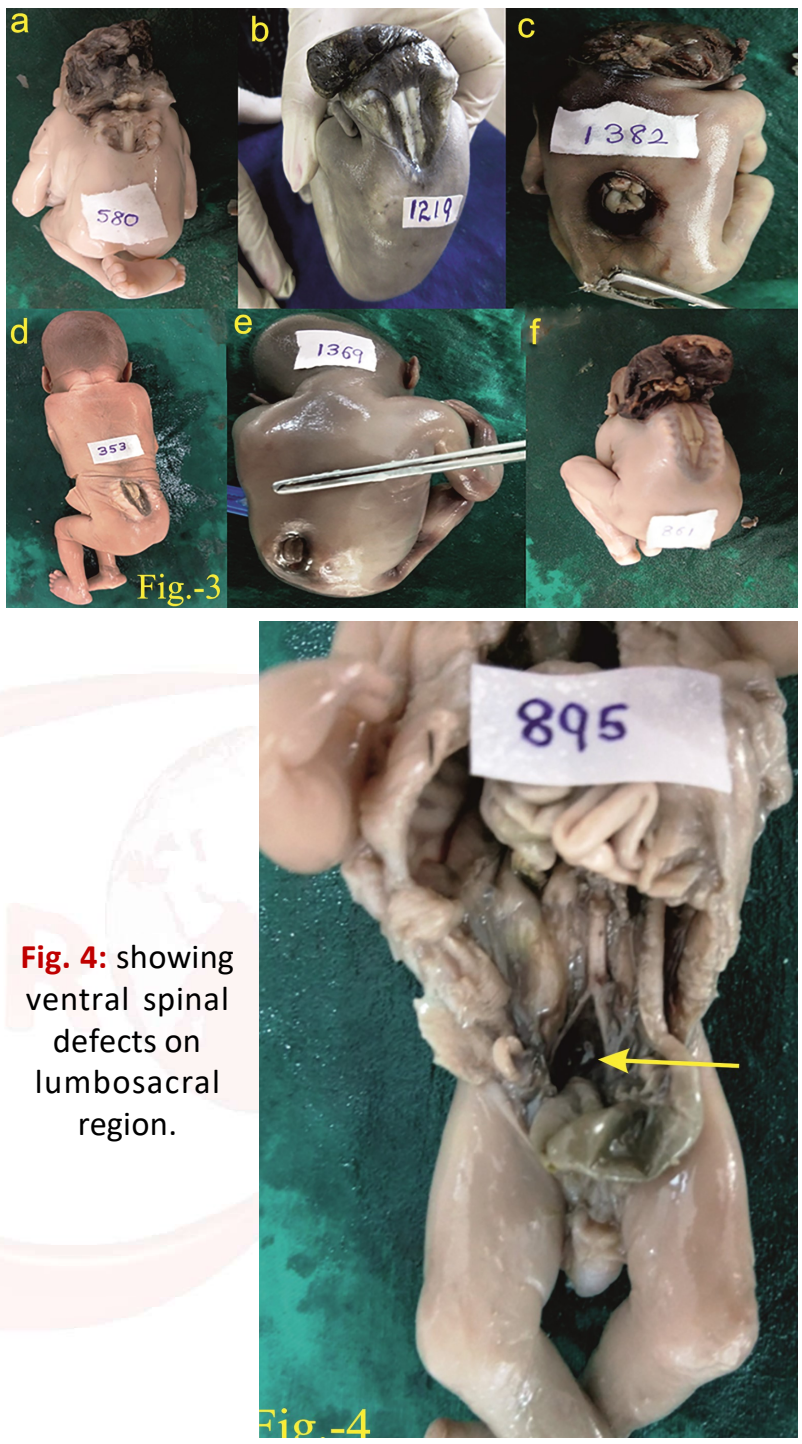

Fig. 4: showing ventral spinal defects on lumbosacral region.

Fig. 5: showing rachischisis defect on whole vertebral length

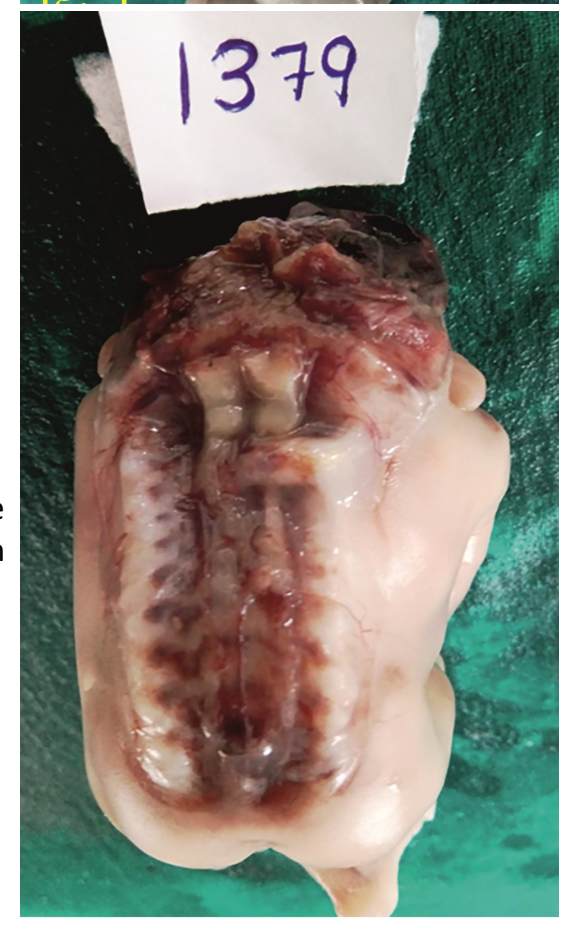


Fig. 6: Showing different type of spinal defects has metioned above.

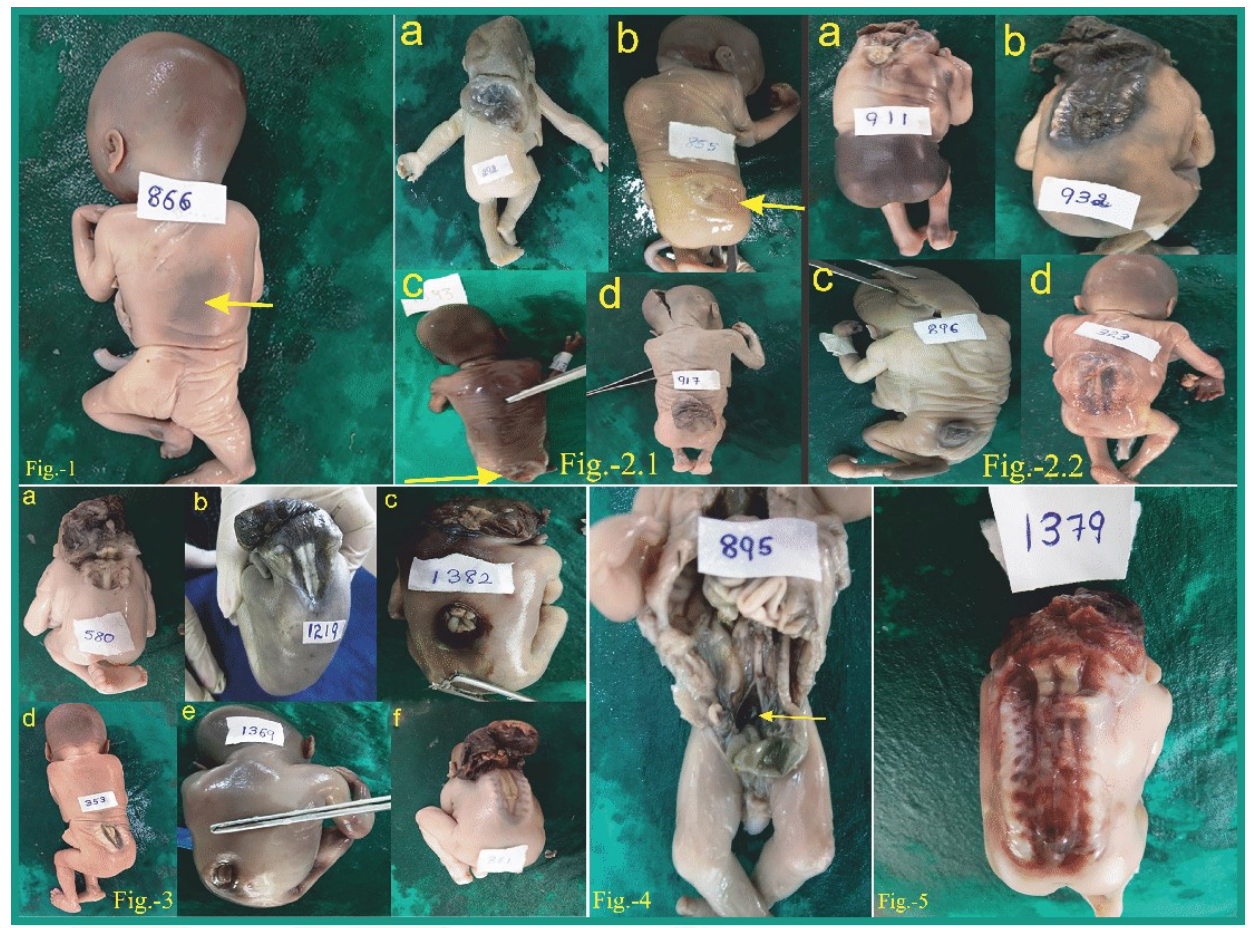

Table 1: Showing morphological classification of spina bifida along with number of spinal defects was found.

\begin{tabular}{|c|c|c|c|}
\hline \multirow{4}{*}{} & Morphology & Type & No: \\
\cline { 2 - 4 } & Spina Occulta (closed) & & 2 \\
\cline { 2 - 4 } Spina & \multirow{3}{*}{ Sifida } & Cutaneous cyst & - \\
\cline { 2 - 4 } & & Meningocele & 52 \\
\cline { 2 - 4 } & Spina Aptica (open) & Myelomeningocele & 40 \\
\cline { 2 - 4 } & $\begin{array}{c}\text { Whole length defect in } \\
\text { spine }\end{array}$ & Myelocele & 47 \\
\cline { 2 - 4 } & Ventral spinal bifid & & 21 \\
\hline
\end{tabular}

Table 2: Showing numbers of spinal defects according to location (region). STDs - spinal tube defects.

\begin{tabular}{|c|c|c|c|c|c|c|}
\hline Location & $\begin{array}{c}\text { Spina bifida } \\
\text { occulta (2 cases) }\end{array}$ & $\begin{array}{c}\text { Meningocele } \\
\mathbf{5 2} \text { cases) }\end{array}$ & $\begin{array}{c}\text { Myelomeningocele } \\
\text { (40 cases) }\end{array}$ & $\begin{array}{c}\text { Myelocele } \\
\text { (47 cases) }\end{array}$ & $\begin{array}{c}\text { Rachischisis } \\
\text { (21 cases) }\end{array}$ & $\begin{array}{c}\text { Ventral spinal } \\
\text { defects (2 cases) }\end{array}$ \\
\hline Cervical & & $7(13 \%)$ & $5(12 \%)$ & $11(23 \%)$ & - & - \\
\hline Thoracic & & $3(5 \%)$ & $6(15 \%)$ & $2(4 \%)$ & - & - \\
\hline Lumber & & $16(30 \%)$ & $11(27 \%)$ & $13(27 \%)$ & - & - \\
\hline Sacral & & $2(3.80 \%)$ & - & - & & \\
\hline Cervicothoracic & & $3(5.70 \%)$ & $1(2.50)$ & $6(12.70 \%)$ & - & - \\
\hline Cervicothoracolumber & & $6(11 \%)$ & - & $1(2 \%)$ & - & - \\
\hline Thoracolumbar & $1(50 \%)$ & $6(11 \%)$ & $8(20 \%)$ & $11(23 \%)$ & - & - \\
\hline Lumbosacral & $1(50 \%)$ & $5(9.6 \%)$ & $8(20 \%)$ & $3(6 \%)$ & - & $2(100 \%)$ \\
\hline Sacrococcygeal & & $4(7.6 \%)$ & $1(2.5 \%)$ & - & - & - \\
\hline Cervicococcygeal & & - & - & - & $21(100 \%)$ & - \\
\hline
\end{tabular}

Table 3: Showing number of cases of associated morphological malformations with spinal defects.

\begin{tabular}{|l|c|l|}
\hline Associated morphological anomalies & Number of cases & \\
\hline Hydrocephalus & $18(15 \%)$ & \\
\hline Arnold chairi malformation & $9(7.7 \%)$ & \\
\hline Anencephaly & $48(41 \%)$ & 3 cases anencephaly with omphalocele and 2 cases with diaphragmatic hernia \\
\hline Club foot & $7(6 \%)$ & \\
\hline Omphalocele & $8(6.8 \%)$ & \\
\hline Diaphragmatic hernia & $9(7.7 \%)$ & \\
\hline Facial defects & $9(7.7 \%)$ & \\
\hline Urogenital anomalies & $6(5 \%)$ & 2 cases with renal agenesis, 3 cases with polycystic kidney, 1 horse shoe shape kidney \\
\hline Kyphosis & $2(1.7 \%)$ & \\
\hline
\end{tabular}


Table 4: showing comparative analysis of spinal anomalies.

\begin{tabular}{|c|c|c|c|c|c|}
\hline S. no: & Author & Year & Number/ Total & $\begin{array}{c}\text { No: of Defect } \\
\text { Cases }\end{array}$ & $\begin{array}{c}\text { Percentage } \\
(\%)\end{array}$ \\
\hline $\mathbf{1}$ & Nielsen & 2006 & 1984 & 38 & $1.91 \%$ \\
\hline $\mathbf{2}$ & Khattak & 2008 & 3310 & 8 & $0.24 \%$ \\
\hline $\mathbf{3}$ & Menasinkai & 2010 & 3000 & 17 & $0.56 \%$ \\
\hline $\mathbf{4}$ & Himabindu & 2015 & 1000 & 5 & $0.50 \%$ \\
\hline $\mathbf{5}$ & $\begin{array}{c}\text { Deepasree } \\
\text { (case report) }\end{array}$ & 2017 & 2 & 2 & - \\
\hline $\mathbf{6}$ & Present Study & 2018 & 1400 & 164 & $11.70 \%$ \\
\hline
\end{tabular}

\section{DISCUSSION}

Spinal defect is the commonest type of congenital anomalies which are major causes of perinatal deaths. In the present study, out of 1400 fetuses, 164 cases were observed spinal anomalies. Out of 164 cases, it was observed that 52 cases [31.7\%] with meningocele (figure no: 2.1 ), 40 cases [24.3\%] with myelomeningocele (figure no: 2.2 ), 47 cases [28.6\%] with myelocele (figure no: 3 ), and 21 cases [12.8\%] with rachischisis (figure no: 5). Two cases with [1.2\%] with spina bifida occulta (figure no: 1 ) and two cases [1.2\%] with ventral spinal defect (figure no: 4) were seen . Meningocele defects ( 52 cases $31.7 \%$ ) were found in maximum number in this study. Most commonly defects were present on thoracolumber region. This study is correlates with Himabindu [6].

In the present study 52 cases [31.7\%] with meningocele ( 7 cases in cervical, 3 thoracic, 16 lumber, 2 sacral, 3 cervicothoracic, 6 cervicothoracic-lumber, 6 thoracolumber, 5 lumbosacral, 4 sacrococcegeal region) (figure no: 2.1 ), rachischisis ( whole vertebral length) (figure no: 5), 2 cases [1.2\%] spina bifida occulta ( 1 case in thoracolumber and another 1 case in lumbosacral region) (figure no: 1 ) and 2 cases [1.2\%] ventral spinal defects in lumbosacral region were found (figure no: 4) [ Table no: 1 \& 2] . The findings also noted by Sharada in 3000 cases, out of these 17 were observed with spinal defects 1 case with rachichiasis, 4 cases with meningocele ( 3 in lumbosacral \& 1 in cervical region)\} [12] and 8 cases of meningocele also reported by Sania [13].

Present study has large numbers of spinal defects were noted in which 2 cases of spina bifida occulta (figure no: 1), 40 myelomeningocele (figure no: 2.2 ), 47 cases with myelocele (figure no: 3), 2 cases of ventral spinal defects (figure no: 4) and 21 rachischisis (figure no: 5) [Table no:2] . Himabindu observed 1000 cases in which they found 5 cases with spinal anomalies. They noted myelocele, myelomeningocele, rachichiasis, spina bifida occulta and meningocele [6]. The probable reasons may be genetic, hyperthermia and drug history which patient has not disclosed to us.

In the present study we noted 21 cases with rachischisis whereas Deepasree found 2 case reports with rachischisis [14].

There were 164 cases with spinal defects of these 116 [70\%] cases has associated anomalies in which 18 [15\%] cases of hydrocephalus, 9 of [7.7\%] arnold Chairi malformation, 48 [41\%] with anencephaly (figure no: 2.2 a, b \& 3 a, b, c $\& f$ ), of these 3 cases have anencephaly along with omphalocele and 2 cases have anencephaly along with diaphragmatic hernia, 7 [6\%] club foot, 8 [6.8\%] omphalocele, 9 [7.7\%] diaphragmatic hernia, 9 [7.7\%] facial defects, 2 [1.7\%] cases with kyphosis and 6 [5\%] cases with urogenital anomalies of theses 3 cases with polycystic kidney, 1 case with horseshoe shaped kidney and 2 cases with renal agenesis were found [ Table no: 3] whereas Nielsen observed 1984 cases in which they found 38 cases with spinal defects. Out of 38 cases, 31 showed spinal defects with associated morphological anomalies in which 18 cases with hydrocephalus, 6 arnold chairi malformation, 3 cases related with lower extremities including club foot/ hypoplasia/ contracture [15]. Comparative analysis of previous studies given in table no: 5. Neuralization occurs within 28 days after fertilization before most of women become aware about their pregnancy. If there is any defect in closure of neural tube in spinal region it leads to spina bifida. 
There are various methods for diagnosing spinal defects prenantally like ultrasounds and determing alpha fetoprotein (AFP) level in maternal serum and amniotic fluid. Performing in utero surgeries till 28 weeks of gestation is a new treatment for such defects [8]. The extensive medical care and surgery have increased the survival rates of children with meningocele and myelomeningocele. The risk of death is dependent on the severity of the lesion and on other factors such as the availability of medical and surgical resources. Spina bifida occulta have chances of evolving asymptomatic through the lifespan of the patient [16]. Spina bifida is a neurogenetic disorder with a complex etiology and involves both genetic and environmental factors. Hyperthermia, valproic acid and hypervitaminosis $A$ are others factors which contribute to neural tube defects. As a result women on anti- epileptic drugs during pregnancy are advised to undergo routine antenantal checkup with AFP.

Recent evidence have indeed confirmed that folic acid reduces the incidence of these spinal neural tube defects by as much as $60-70 \%$ provided $400 \mu \mathrm{g}$ is taken daily beginning 2 months prior to conception and continuing throughout gestation [8]. A strong inhibitor of DNA synthesis- cyclophosphamide which cause anti proliferative activity of axial mesoderm leading to axial skeleton malformations results defects in skull vault and vertebral column. In spinal defect, neural fold remain open result bifid vertebral column [17]. Some of the studies have shown spinal defects associated with gene C677T. PCP (Planar Cell Polarity) genes are also related with spina bifida [18-21].

\section{Study Limitations:}

Department is not having the liable genetic lab and hormonal study i.e study is not associated with genes like C677T and PCP.

\section{CONCLUSION}

Spinal defects are occurring in north Indian population at the rate of $11.7 \%$ by doing routine autopsies. The spina bifida with meningocele was seen in $31.7 \%$ of cases whereas spina bifida occulta and ventral spinal defects were seen in $1.2 \%$ in each type. The ventral spinal defects have been not reported in previous study. In early stages of gestation, detection of congenital anomalies is very important. Early detection of congenital anomalies is advantageous to the obstetrician to plan the line of management by deciding whether to continue or terminate the pregnancy.

\section{Conflicts of Interests: None}

\section{REFERENCES}

[1]. Park K. Park's Textbook of Preventive and Social Medicine.18 ${ }^{\text {th }}$ edition. 2005; 423-425.

[2]. Sankar VH, Phadke SR. Clinical utility of fetal autopsy and comparison with prenatal ultrasound findings. J Perinatol. 2006; 26: 224-229.

[3]. Mitchell LE. Epidemiology of neural tube defects. Am J Med Genet C Semin Med Genet, 2005; 135: 8894.

[4]. Andrew JC and Nicholas DEG. Genetics and Development of neural tube defects. J Pathol. 2010; 220: 217-230.

[5]. Aguilera S, Soothill P, Denbow M, Pople I. Prognosis of spina bifida in the era of prenatal diagnosis and termination of pregnancy. Fetal Diagn Ther. 2009; 2: 68-74.

[6]. Himabindu N, Asra A, Saritha S, Ramani, Nagajyothi D, Gayathri P. Comprehensive study of neural tube defects in 1000 foetuses with clinical spectrum. Int J Anat Res. 2015; 3:1456-1462.

[7]. Oakeshott P, Hunt GM, Poulton A, Reid F. Open spina bifida: birth findings predict long-term outcome. Arch Dis Child. 2012; 97:474-476.

[8]. Sadler TW. Langman's Medical Embryology.11 ${ }^{\text {th }}$ edition. Lippincott - Wilkins, Philadelphia, London. 2009; 302-316.

[9]. Sperber GH, Gorlin RJ. Head and neck. In: GilbertBarness E, editor. Potter's Pathology of the Fetus and Infant. St. Louis, MO, USA: Mosby-Year Book, 1997.

[10]. Larroche JC, Encha-Razavi F, de Vries L. Central nervous system. In: Gilbert-Barness E, editor. Potter's Pathology of the Fetus and Infant. St. Louis, MO, USA: Mosby-Year Book 1997.

[11]. Squier MV. Malformations of the central nervous system and hydrocephalus. In: Keeling JW, editor. Fetal and Neonatal Pathology 3rd edition. London: Springer: 2001.

[12]. Menasinkai BS. A study of neural tube defects. J Anat. Soc India. 2010; 59:162-167.

[13]. Khattak TS, Naheed T, Akhtar S,Jamal T. Incidence and Risk Factors for Neural Tube Defects in Peshawar. Gomal journal of Medical Sciences. 2008; $6: 1-4$.

[14]. Deepasree Jaganmohan, Prema Subramaniam, Nagarajan Krishnan, Preetam Mahajan. Two cases of craniospinal rachischisis totalis: Role of magnetic resonance imaging in diagnosis and review of neural tube defects in the Indian context with implications for folate fortification. Journal of pediatric Neurosciences. 2017; 12: 32-35. 
[15]. Nielsen LAG, Maroun LL, Broholm H, Laursen H, Graem N. Neural tube defects and associated anomalies in a fetal and perinatal autopsy series. APMIS. 2006; 114:239-246

[16]. Botto LD, Moore CA, Khoury JM, Erickson JD. Neural tube defects - Review articles. Medical Progress. 1999; 341:1509-1517.

[17]. Padmanabhan R, Singh S. Axial Skeletal Malformations Associated with Cranioschisis Aperta and Exencephaly. Actaorthop. 1983; 54:104-112.

[18]. M. R. Amorim,M. A. C. Lima, E. E. Castilla, and I. M. Orioli, "Non-Latin European descent could be a requirement for association of NTDs and MTHFR variant $677 \mathrm{C}>\mathrm{T}$ : a metaanalysis,"American Journal of Medical Genetics Part A. 2007; 143:1726-1732.
[19]. Doudney K, Moore GE, Stanier P, Ybot- Gonzalez P, Paternotte C, Greene NDE, et al. "Analysis of the planar cell polarity gene Vangl 2 and its co-expressed paralogue Vangl1 in neural tube defect patients". American Journal of Medical Genetics. 2005; 136: 90-92.

[20]. Lei Y, Zhu H, Yang W, Ross ME, Shaw GM, and Finnell $\mathrm{RH}$. "Identification of novel CELSR1 mutations in spina bifida." PLoS ONE. 2014; 9: 1-3.

[21]. Kibar Z, Torban E, McDearmid JR, Reynolds A, Berghout J, Mathier $\mathrm{M}$, et al. "Mutations in VANGL1 associated with neural-tube defects." New England Journal of Medicine, 2007; 356:1432-1437.

How to cite this article:

Amandeep Kaur, Mahesh Sharma SPINA BIFIDA - A RETROSPECTIVE STUDY. Int J Anat Res 2019;7(2.1):6390-6396. DOI: 10.16965/ ijar.2019.124 